\title{
Audiências públicas: fatores que influenciam seu potencial de efetividade no âmbito do Poder Executivo federal
}

Igor Ferraz Fonseca, Raimer Rodrigues Rezende, Marília Silva de Oliveira e Ana Karine Pereira

\section{Introdução}

Este artigo apresenta as principais conclusões de pesquisa realizada no âmbito do Instituto de Pesquisa Econômica Aplicada (Ipea), que buscou responder à seguinte pergunta: "no âmbito do Poder Executivo federal, quais são os principais fatores que influenciam o potencial de efetividade das audiências públicas como mecanismo de participação social no processo de gestão das políticas públicas?””.

O estudo se estrutura a partir do conceito de pesquisa aplicada, tendo como foco a melhoria do processo de organização e gestão de audiências públicas (AP). A pesquisa teve a duração de um ano e contou com análise bibliográfica, entrevistas com gestores públicos e profissionais atuantes em organizações não governamentais, além de quatro estudos de caso de audiências públicas realizadas por órgãos do governo federal: a elaboração do Plano Nacional de Resíduos Sólidos (PNRS); a discussão sobre as minutas do Edital de Licitação e Contrato de Permissão dos Serviços de Transporte Rodoviário Interestadual de Passageiros 
e o licenciamento ambiental de dois grandes projetos de hidrelétricas - Santo Antônio e Jirau, em Rondônia, e Belo Monte, no Pará. Este artigo está dividido conforme as seguintes seções:

A seção Qualidade da participação apresenta um referencial teórico relacionado à avaliação de processos participativos. Embora seja um tema bastante atual na literatura especializada, não há consenso sobre como realizar uma avaliação objetiva sobre a efetividade de processos participativos, entre eles as audiências públicas. No entanto, a literatura converge quando aponta que focar na melhoria do desenho institucional das audiências públicas e na busca pela eficiência e democratização dos mecanismos internos de coordenação e de participação são iniciativas fundamentais para ampliar a efetividade desses espaços.

Uma das dificuldades encontradas na presente pesquisa esteve relacionada à escassez de estudos sobre audiências públicas. Diferentemente de outros instrumentos participativos (tais como conselhos e conferências de políticas públicas), a bibliografia sobre audiências públicas é rarefeita, carecendo de uma sistematização de seus atributos básicos. Assim, na tentativa de suprir essa lacuna e também de fornecer a base para as demais etapas dessas pesquisas, realizamos um esforço focado na definição dos atributos básicos deste mecanismo de participação social. Esse esforço é apresentado na seção Definição de audiência pública (AP).

A seção Metodologia da Pesquisa apresenta a metodologia empregada na pesquisa, que foca em metodologia de pesquisa qualitativa. A seção Estudo de caso, por sua vez, apresenta breve contextualização dos quatro estudos de caso. Por fim, a seção Resultados e Discussão apresenta os principais resultados e conclusões da pesquisa. Tais resultados são apresentados e discutidos a partir dos elementos empíricos observados na análise dos estudos de caso.

\section{Qualidade da participação}

Após um processo de grande expansão e diversificação ancorada nas inovações institucionais promovidas pela Constituição Federal de 1988, o Brasil conta com um leque de processos participativos - que promovem a interface entre Estado e sociedade - institucionalizados no âmbito do governo federal, compreendendo mais de 90\% dos programas e políticas públicas nacionais (PIRES \& VAZ, 2010).

Com relação a essas instituições participativas, há diversos estudos sobre conselhos e conferências nacionais (ver, p. ex., FonseCa et al., 2012; AlenCAR et al., 2012; Souza, 2012; Avritzer, 2012; Pogrebinschi, 2012). Já as audiências públicas continuam sendo pouco estudadas, apesar de sua alta frequência em políticas de infraestrutura e de regulação do setor privado, a exemplo do licenciamento ambiental e de processos coordenados por agências reguladoras.

A ampliação desses estudos tem cada vez mais priorizado a questão da efetividade (IpeA, 2011; Avritzer, 2010). O diagnóstico é que há dúvidas se os processos participativos estão de fato ampliando os processos democráticos (Cleaver, 2001, 2005; Kothari, 2001; Sayago, 2007; Manor, 2004; Fuks \& Perissinotto, 2006) e contribuindo para o aperfeiçoamento de políticas públicas. No entanto, averiguar e mensurar a efetividade de espaços participativos é tarefa complexa e não encontra consenso na literatura especializada (PIREs et al., 2011). 
Diante disso, autores como Pires et al. (2011) apontam que os estudos que analisam a qualidade de processos participativos podem identificar fatores fortemente relacionados com a efetividade. A qualidade de processos participativos está relacionada com o desenho institucional dos mecanismos de participação social; com as regras e normas que condicionam seu funcionamento; com a atuação e recursos mobilizados por governo e sociedade; pela manifestação de relações de poder; entre outros.

A premissa é que, mesmo sem um consenso sobre como mensurar a efetividade de instituições participativas, ações concretas visando a aperfeiçoar o desenho, as regras e o processo democrático no interior desses mecanismos participativos contribuem tanto para ampliar sua efetividade no que se refere ao aperfeiçoamento de políticas públicas - quanto para ampliar a legitimidade desses espaços de interação entre Estado e sociedade, implicando uma nova forma de processo decisório nas políticas públicas (PIres et al., 2011).

Dessa forma, esta pesquisa pretende contribuir para o alcance de políticas públicas mais legítimas e efetivas, por meio da identificação de fatores que contribuem para a ampliação da qualidade do processo participativo em audiências públicas.

\section{Definição de audiência pública (AP)}

Não há consenso em relação a uma definição de audiência pública na literatura sobre participação social e tampouco nas políticas e ações realizadas pelo Poder Executivo federal.

As fontes utilizadas nesta pesquisa para definir audiência pública, delimitando, assim, o objeto de estudo, incluem sistematização da literatura disponível sobre o assunto, entrevistas com burocratas do governo federal e representantes da sociedade civil com grande experiência em AP, além de análise dos dados sobre audiências públicas contidos no Sistema de Informações Gerenciais de Planejamento do Governo Federal (SIGPlan), do Ministério do Planejamento, Orçamento e Gestão ${ }^{1}$.

Entre os resultados, identificou-se que as audiências públicas têm caráter consultivo e não deliberativo (SOARES, 2002;

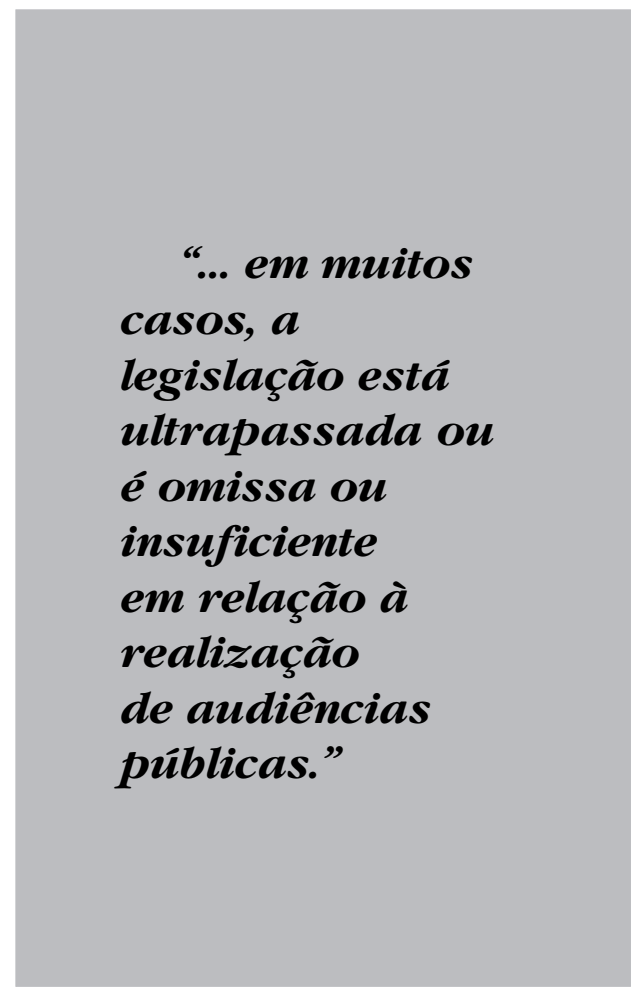

VAsConcelos, 2000). Nas AP, o governo federal tem maior discricionariedade do que em outros fóruns participativos, tais como em conselhos deliberativos. Assim, além de gerar transparência sobre os atos governamentais, uma AP visa também a colher opiniões e propostas da população. Cabe, entretanto, à administração acatar ou não as propostas. 
Além disso, as AP têm caráter pontual. Diversas instituições participativas, como os conselhos gestores, são perenes, com atribuições permanentes relacionadas a uma área de política pública. A existência de um conselho não está vinculada a uma ação governamental específica, pois promove a articulação permanente entre Estado e sociedade civil. Ao contrário, as AP são invariavelmente vinculadas a um processo decisório específico, seja ele a elaboração de um plano, a elaboração de normas regulatórias, a avaliação de uma ação governamental ou mesmo a correção de rumos nas políticas públicas. Outra característica é o caráter presencial das AP, que não podem ser realizadas pela internet ou por intercâmbio documental (SOARES, 2002; Mattos, 2004; Grau, 2011). O caráter presencial da audiência pública está relacionado à possibilidade de manifestação oral dos participantes, não excluindo, entretanto, a possibilidade de manifestação por escrito (SoAres, 2002; Grau, 2010). Além disso, o ideal é que se propicie o debate entre os atores interessados (SOARES, 2002; Grau, 2010; Barros \& Ravena, 2011; Serafim, 2007). Esse último ponto aproxima as AP de outros fóruns participativos, tais como os conselhos gestores, o orçamento participativo e as conferências de políticas. Ao mesmo tempo, essa característica distancia as AP de outras formas "individualizadas" de interface entre Estado e sociedade civil, tais como as consultas públicas e as ouvidorias. Ressalta-se que, embora seja possível a participação de atores individuais, a audiência pública tem caráter coletivo e não pode excluir atores não organizados do processo participativo. Assim, uma AP é aberta a todos os interessados. A possibilidade de manifestação de interesses e opiniões de cidadãos não organizados é uma diferença clara entre a AP e espaços de participação com caráter formalmente representativo - como os conselhos e as conferências.
Além disso, as AP possuem regras específicas para o seu funcionamento, como procedimentos formais e orientações metodológicas, tais como data e hora definidas, pauta, atas de reunião, determinação de gravação em vídeo e/ou de voz dos debates (Soares, 2002; Mattos, 2004). Há também regras relacionadas à condução do debate, tais como a determinação de quais atores têm a palavra, quanto tempo de fala tem cada participante, se haverá réplicas, tréplicas, entre outras. Por fim, há regras que visam a orientar a sistematização da opinião dos atores e a incorporação de suas demandas na política ou na ação com a qual a AP está relacionada.

A partir do exposto acima, esta pesquisa adotou uma definição de audiência pública composta das características elencadas no Quadro 1.

\section{Metodologia da pesquisa}

Esta pesquisa ocorreu entre dezembro de 2011 e dezembro de 2012, utilizando as seguintes fontes de dados: levantamento bibliográfico sobre participação social e sobre audiências públicas; sistematização das principais leis e demais atos normativos que tratam de audiências públicas; análise dos registros de realização de audiências públicas no âmbito dos programas do governo federal, disponíveis em banco de dados do SIGPlan; e realização de quatro estudos de caso. Foi feito o acompanhamento das AP que ocorreram durante o período da pesquisa ${ }^{2}$. No caso das AP que já haviam ocorrido ${ }^{3}$, foi feita uma análise das gravações de áudio e/ou vídeo. Todos os casos contaram com análise documental, bem como entrevistas com participantes e organizadores. Para a seleção dos casos, além dos critérios relacionados à sua relevância e à viabilidade, optou-se por uma estratégia dupla. Por um lado, foram 


\section{Quadro 1: Definição de audiência pública}

\begin{tabular}{|l|l|}
\hline \multirow{4}{*}{$\begin{array}{l}\text { Características básicas das } \\
\text { audiências públicas }\end{array}$} & Possui caráter consultivo. \\
\cline { 2 - 3 } & Possui caráter pontual. \\
\cline { 2 - 3 } & Possui caráter presencial. \\
\cline { 2 - 3 } & Possui caráter coletivo. \\
\cline { 2 - 3 } & Pressupõe manifestação oral dos participantes. \\
\cline { 2 - 2 } & Implica debate entre os atores envolvidos. \\
\hline & É aberta a todos os interessados. \\
\hline & Contém regras específicas para o seu funcionamento. \\
\hline
\end{tabular}

Fonte: Elaboração própria.

escolhidos casos que representassem a maior diversidade possível, por outro lado, foram escolhidos dois casos relativamente semelhantes, ambos de licenciamento ambiental de grandes empreendimentos, que correspondem ao padrão mais frequente de utilização de audiências públicas pelo governo federal (ver IPEA, 2012).

A metodologia utilizada nos estudos de caso foi baseada em dois conjuntos de dimensões de análise (ver Quadro 2). As dimensões que caracterizam o processo se relacionam à análise da qualidade do processo de planejamento e condução das audiências públicas, buscando identificar os principais fatores que influenciam seu potencial de efetividade e, portanto, as causas de sucessos e insucessos. As dimensões para a análise do resultado levam em conta os objetivos desse mecanismo de participação social e têm por função orientar a avaliação da efetividade de determinada audiência pública, ou seja, seu impacto na sociedade.

Por meio da lista de dimensões, objetivou-se também criar uma referência para gestores ou pesquisadores interessados em analisar outros processos, tendo em vista a possibilidade de adaptá-la de acordo com os objetivos e possibilidades de cada pesquisa. Por essa razão, foram incluídas também dimensões que não teriam como ser analisadas com profundidade nos estudos de caso da presente pesquisa, devido a seus objetivos e limites de escopo e tempo.

\section{Estudos de caso ${ }^{4}$}

\section{Elaboração do Plano Nacional de Resíduos Sólidos (PNRS)}

A Política Nacional de Resíduos Sólidos, criada pela Lei n⿳⺈ 12.305/2010, estabeleceu o Plano Nacional de Resíduos Sólidos (PNRS) como um de seus principais instrumentos de gestão. Essa lei, regulamentada pelo Decreto ํㅡㄴ 7.404/2010, instituiu o Comitê Interministerial (CI), composto por 12 ministérios, responsável pela elaboração, coordenação e implementação do PNRS, com a coordenação do Ministério do Meio Ambiente (MMA). Uma primeira versão do PNRS foi elaborada a partir do diagnóstico da situação dos resíduos sólidos, cenários, metas, diretrizes e estratégias para o cumprimento das metas ${ }^{5}$ (Brasil, 2011). Essa versão, como estabelecida em lei, foi submetida ao debate com a sociedade civil por meio de cinco 


\section{Quadro 2: Dimensões de análise}

\section{Dimensões que caracterizam o processo}

- Atos normativos e seus impactos no processo

- Mapeamento dos principais atores

- Características relevantes do responsável pelas AP

- Desenho e processo de realização das AP

- Momento da participação e timing do processo

- Escopo e amplitude do debate

- Mobilização e representatividade dos participantes

- Recursos (inclusive humanos) e infraestrutura disponibilizados, e organização do evento

- Processo preparatório para as AP

- Condução da AP, metodologia e efetividade das regras procedimentais

- Sistematização das propostas e devolutiva

- Transparência

\section{Dimensões de resultado}

- Impacto na tomada de decisão e em compromissos políticos

- Mediação: diminuição de conflitos e aumento da cooperação

- Construção de capacidades (capacity building)

- Divulgação das ações governamentais

Fonte: Elaboração própria.

audiências públicas regionais e uma nacional, nas quais os participantes puderam fazer emendas e sugestões ao texto. Essas audiências ocorreram entre setembro e dezembro de 2011.

O MMA coordenou o processo de interlocução com estados e sociedade para a realização das $\mathrm{AP}$, com a colaboração de representantes de outros ministérios que compõem o Comitê Interministerial. Foi utilizada uma metodologia comum em todas as AP, de forma que pudessem padronizar o trabalho e as formas de contribuição. Os pesquisadores do Ipea acompanharam todas as seis audiências realizadas pelo MMA, bem como procederam à análise documental e realização de entrevistas com organizadores e participantes.

\section{Licitação e Contrato de Permissão dos Serviços de Transporte Rodoviário Interestadual de Passageiros}

Foram estudados dois processos de audiência pública: 1) a audiência pública $\mathrm{n}^{\mathrm{Q}}$ 120/2011, que colocou em discussão o plano de outorga ${ }^{6}$ sobre os serviços de transporte rodoviário interestadual de passageiros, operados por ônibus do tipo rodoviário; 2) a audiência pública $\mathrm{n}^{\mathrm{O}} 121$ / 2011, que teve como objetivo coletar contribuições sobre as Minutas do Edital de Licitação e Contrato de Permissão dos Serviços de Transporte Rodoviário Interestadual de Passageiros, da Agência Nacional de Transportes Terrestres (ANTT).

Esses dois processos de audiências públicas se desdobraram em sessões públicas em diferentes cidades, as quais 
seguiram rigorosamente as mesmas regras e não houve diferença entre as audiências, a não ser o lugar onde foram realizadas.

Pesquisadores do Ipea acompanharam presencialmente as sessões públicas que estavam em andamento, vinculadas à AP $121 / 2011$, realizadas entre janeiro e março de 2012. Além disso, foram analisadas as atas das sessões públicas vinculadas à AP 120/2011, que aconteceram entre agosto e outubro de 2011. Foram realizadas entrevistas com organizadores e participantes.

\section{Licenciamento das hidrelétricas de Santo Antônio e Jirau, em Rondônia}

Este estudo de caso analisou as audiências públicas realizadas, em 2006, no âmbito do licenciamento ambiental das usinas hidrelétricas de Santo Antônio e Jirau, no Estado de Rondônia, iniciado em 2003. Este estudo de caso utilizou, em primeiro lugar, informações coletadas em 2009, por ocasião de uma pesquisa de mestrado sobre o processo de licenciamento em questão (REzende, 2009). Para a presente pesquisa, foi feito novo estudo bibliográfico e trabalho de campo em Porto Velho (RO) e em Brasília (DF), com entrevistas, análise das gravações de áudio e vídeo das AP e nova análise dos autos do processo de licenciamento. Ao todo, foram entrevistadas 51 pessoas do governo, da sociedade civil e do setor privado. Além da análise dos autos do processo, foram analisados também diversos outros documentos (relatórios do Ministério Público, da Fundação Nacional do Índio -Funai - etc.).

As barragens de Santo Antônio e Jirau formam, juntas, um dos maiores projetos de geração de energia elétrica na Amazônia e teriam uma potência instalada de 6.450 MW (3.150 MW em Santo Antônio e 3.300 MW em Jirau). Ambas as usinas estavam sendo construídas no momento desta pesquisa, no Rio Madeira, no Município de Porto Velho, capital do Estado de Rondônia. O Rio Madeira é o segundo maior rio da Bacia Amazônica e o principal tributário do Rio Amazonas. Sua bacia inclui também territórios da Bolívia e do Peru e é uma das áreas mais ricas em biodiversidade do mundo (OrTIZ, 2007). Além disso, a construção das usinas de

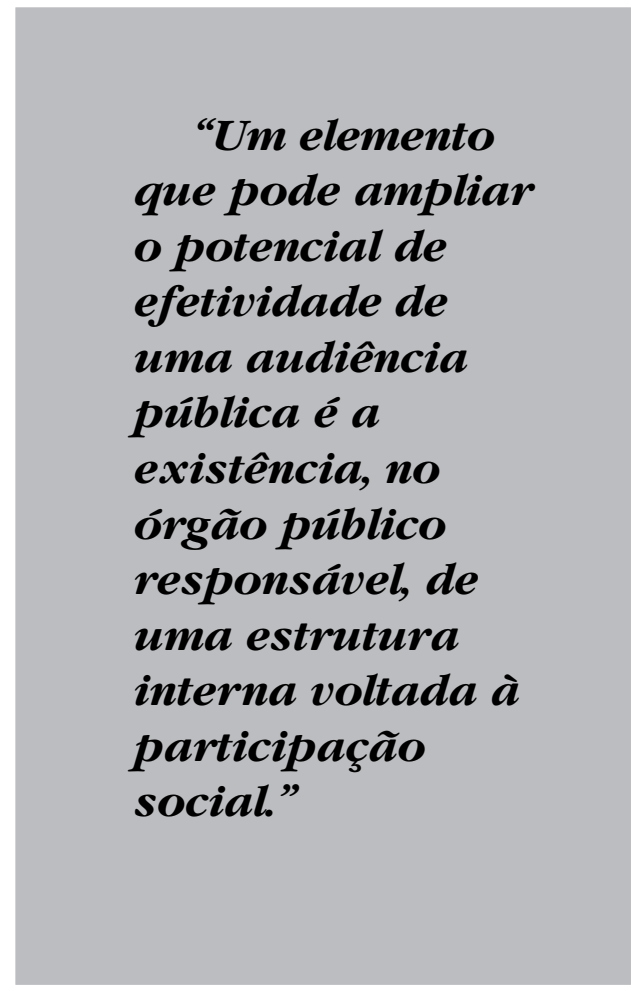

Santo Antônio e Jirau foi considerada uma prioridade estratégica para o governo federal e, por isso, foi incluída no Programa de Aceleração do Crescimento (PAC) como um dos seus principais projetos.

Após um longo processo marcado por protestos da sociedade civil e processos judiciais visando a suspender o processo de licenciamento ambiental (que contempla a 
realização de audiências públicas), as AP aconteceram em novembro de 2006, nos municípios de Jacy-Paraná, Porto Velho, Abunã e Mutum-Paraná, com, respectivamente, 800, 1100, 404 e 669 participantes.

\section{Licenciamento da hidrelétrica de Belo Monte, no Pará}

A usina de Belo Monte está sendo construída no Estado do Pará, no Rio Xingu, um dos principais afluentes do Rio Amazonas, próximo à cidade de Altamira e à rodovia federal Transamazônica (BR230), numa região caracterizada pela existência de grande quantidade de floresta nativa, pecuária e agricultura (SouzA \& REID, 2010). A responsável pela construção da usina é a Norte Energia S.A, composta por empresas estatais e privadas do setor elétrico.

Apesar de ser um projeto antigo e multifacetado, este estudo se limitou à análise do processo de participação social coordenado pelo Ibama como parte do licenciamento ambiental, iniciado em $2006^{7}$.

As primeiras audiências relacionadas ao licenciamento do empreendimento de Belo Monte datam de agosto de 2007, realizadas com o objetivo principal de obter informações para o termo de referência do Estudo de Impacto Ambiental (EIA) a ser feito. No entanto, essas audiências são consideradas pelo Ibama como informais, porque não têm caráter obrigatório, já que a resolução no 9/87 do Conama somente prevê AP após a conclusão do EIA, para sua avaliação.

Além dessas AP informais, o processo participativo que antecedeu as audiências públicas obrigatórias incluiu, em 2009, reuniões em 12 comunidades indígenas, coordenadas pela Funai e com a colaboração do Ibama.
Por fim, em novembro de 2009, ocorreram quatro audiências públicas nos municípios de Brasil Novo, Vitória do Xingu, Altamira e Belém. Essas audiências constituíram o foco desta pesquisa por serem, ao contrário dos eventos que as antecederam, consideradas audiências formais e obrigatórias, de acordo com a Resolução nº 9/87 do Conama.

A metodologia utilizada neste estudo de caso incluiu múltiplas fontes. Foi feita uma revisão bibliográfica com o objetivo de obter informações sobre o histórico do processo, os atores e interesses envolvidos e as alterações no projeto inicial da usina. Em seguida, foram estudados os autos do processo de licenciamento ambiental. Foram realizadas entrevistas qualitativas, em Altamira, com atores que estiveram presentes nas audiências e que têm tido uma atuação ativa no processo decisório de Belo Monte; em Brasília, com funcionários do Ibama envolvidos no licenciamento da obra e que estiveram presentes nas audiências. Além disso, foram assistidas as gravações das quatro audiências formais.

\section{Resultados e discussão}

Nesta seção, são apresentados os principais resultados e conclusões desta pesquisa. O formato de apresentação segue as dimensões de análise que orientaram a pesquisa $^{8}$ e foca em como determinados fatores e características podem influenciar - positivamente ou negativamente - o potencial de efetividade de uma audiência pública. Tais análises foram baseadas nos estudos de caso realizados nesta pesquisa e se utilizam de ilustrações retiradas deles. Apesar de não serem passíveis de generalização, tais resultados são úteis para gestores públicos envolvidos na organização de processos participativos e para 
estudiosos interessados em aprofundar o conhecimento de um campo de pesquisa ainda pouco explorado.

\section{Atos normativos}

Previsões em atos normativos a respeito da realização de AP podem, por um lado, garantir as condições mínimas necessárias para a efetividade da participação, mas podem também, por outro lado, engessar o processo, limitando a ação dos gestores.

O mapeamento que realizamos da utilização de audiências públicas no âmbito do governo federal evidenciou que grande parte delas ocorre em observância a atos normativos. Como consequência, em um grande número de casos, previsões em leis, decretos, resoluções, instruções normativas e/ou portarias determinam, mesmo que em parte, como as audiências devem ser realizadas, tendo impactos diversos no seu potencial de efetividade. Nesse sentido, as previsões normativas podem contribuir para aumentar a transparência do processo participativo, ao garantir o acesso aos documentos relevantes e demais informações importantes e ao apresentar de forma clara prazos e regras para a manifestação. Tais atos normativos também podem aumentar o potencial de efetividade da audiência, ao estipular uma metodologia a ser utilizada, que contribua para uma maior participação, ao mesmo tempo em que permita a sistematização das contribuições e exija uma devolutiva do órgão governamental para a sociedade que explicite quais contribuições foram aceitas, quais não e por quê.

Concluímos que, em muitos casos, a legislação está ultrapassada ou é omissa ou insuficiente em relação à realização de audiências públicas. Nos casos estudados de licenciamento ambiental, observou-se que a legislação vigente está ultrapassada e teve impacto negativo na efetividade da participação. As tentativas do Ibama de fazer mais do que a legislação exige - por exemplo, realizando reuniões públicas para discutir o termo de referência do Estudo de Impacto Ambiental - evidenciam essa deficiência normativa. As resoluções do Conselho Nacional de Meio Ambiente (Conama) somente preveem a obrigatoriedade de realização de audiências públicas para licenciamento ambiental no momento de avaliação do Estudo de Impacto Ambiental. Em relação a comunidades indígenas e povos tradicionais, no caso de empreendimentos que tenham impacto em seus territórios ou modo de vida, vale ressaltar que o Brasil ratificou a Convenção 169 da Organização Internacional do Trabalho, a qual prevê a consulta prévia aos povos indígenas e tribais. No entanto, até o momento desta pesquisa, o mecanismo de consulta prévia ainda não havia sido devidamente regulamentado ${ }^{9}$. Os estudos de caso de hidrelétricas apontam que audiências públicas anteriores à realização do EIA podem ser úteis para que a sociedade possa contribuir na definição de quais temas são importantes de serem estudados. Além disso, audiências públicas no momento de planejamento dos empreendimentos, bem como audiências com foco em públicos específicos - como indígenas, quilombolas e ribeirinhos podem ser necessárias para ampliar a inclusão social e garantir a expressão de todas as opiniões e interesses envolvidos na questão.

Um exemplo positivo é o das audiências realizadas pela Agência Nacional de Transportes Terrestres (ANTT), as quais seguem regras procedimentais expressas em documentos públicos que disciplinam o processo de participação e o controle 
social. Para os servidores da agência, há ainda um manual interno que orienta suas ações sobre o processo participativo. A atenção a essas normas amplia o potencial de efetividade ao aumentar a transparência do processo e indicar as etapas a serem seguidas. É importante ressaltar, contudo, que os atos normativos devem permitir certa flexibilidade para que seja possível corrigir problemas identificados na audiência pública, permitindo o aprendizado e aperfeiçoamento.

Por último, é importante que o prazo para a realização das audiências, contido nos atos normativos, seja compatível com a complexidade da temática e com o grau de organização e peculiaridades do públicoalvo. Essas características podem ser ilustradas pelo caso das audiências de elaboração do Plano Nacional de Resíduos Sólidos. O Decreto n⿳ำ 7.404/2010 determinava o prazo de 180 dias para a elaboração do referido plano. Dentro desses 180 dias, deveriam ser realizados todos os estudos técnicos necessários; a organização e mobilização para, no mínimo, cinco audiências públicas regionais e uma audiência pública nacional; consulta pública via internet, e a sistematização das contribuições da sociedade e o prazo para a elaboração e publicação da versão preliminar do plano. A necessidade de celeridade dificultou as atividades de mobilização, divulgação prévia de documentos e sistematização das contribuições sociais.

\section{Momento de realização das audiên- cias públicas}

É fundamental atentar para o momento do ciclo de política pública em que as audiências públicas ocorrem, tendo em vista que a AP foca em um processo decisório específico, tendo caráter pontual e não permanente. Por um lado, o processo participativo deve ocorrer em um momento no qual ainda seja possível incorporar demandas e valores dos atores envolvidos na temática. Isso pode envolver eventos preparatórios ao processo de audiência pública, no sentido de incluir atores antes excluídos do processo decisório e nivelar conhecimento entre os participantes. Por outro lado, se a AP é realizada em um momento muito inicial do ciclo de política, pode ser que informações necessárias para uma participação informada ainda não estejam disponíveis ou que não haja tempo suficiente para a devida mobilização das partes interessadas e difusão de conhecimento sobre o assunto. Uma solução por vezes sugerida seria a realização de diversas $\mathrm{AP}$ em momentos estratégicos do ciclo de política.

Nos estudos de caso de licenciamento ambiental, foi patente a insatisfação de representantes da sociedade civil quanto ao momento de realização das audiências. Nesses casos, as audiências públicas formais (de caráter obrigatório) ocorreram seguindo as resoluções do Conama, somente após a publicação do EIA e seu respectivo Relatório de Impacto do Meio Ambiente (EIA-Rima). Nesse momento, decisões importantes já haviam sido tomadas, tais como a definição dos temas a serem analisados no EIA. Além disso, deficiência na participação social em momentos anteriores ao licenciamento traz para os debates do licenciamento temas fora do seu escopo, que deveriam ter sido amplamente discutidos anteriormente, como a escolha do local para o empreendimento e a definição das principais características do projeto.

Em ambos os casos de licenciamento estudados, houve processos preparatórios para as AP que visaram a incluir populações ribeirinhas e/ou indígenas. Entretanto, 
eles foram muito criticados pela sociedade civil. No caso de Santo Antônio e Jirau, o processo prévio foi criticado por incluir somente comunidades ribeirinhas, excluindo outras populações tradicionais, e por ter tido um início muito tardio. Tanto no caso de Santo Antônio/Jirau quanto no caso de Belo Monte, faltou uma conexão clara entre essas reuniões com populações tradicionais e as audiências públicas formais. No primeiro caso, houve uma sistematização das demandas, mas que, no entanto, não foi discutida nas AP e a qual foi criticada por parecer uma lista de desejos (wish list). No segundo caso, não houve sistematização. Apesar das falhas, esses processos contribuíram, mesmo que de maneira limitada, para a inclusão, no debate, das populações afetadas, evidenciando a necessidade de sua ocorrência. Nesse sentido, ficou claro que a regulamentação da participação social em um momento anterior às AP atualmente previstas como obrigatórias pode ter um impacto positivo.

No caso do processo de elaboração do PNRS, por sua vez, há razões para crer que as audiências foram realizadas em momento ideal. Se, por um lado, já havia um substrato legal que determinava a elaboração do plano, bem como um texto preliminar para a consulta da sociedade civil, por outro, a participação ocorreu em um momento de planejamento da política, em que foram discutidas diretrizes, ações e metas que iriam compor a política pública. Essa abertura por parte do governo para permitir o acesso a decisões-chave da política aumentou as chances de cooperação entre governo e sociedade civil, potencializando a efetividade das audiências.

O caso da ANTT ilustra outra faceta da temporalidade na realização das audiências. A audiência pública n $\mathrm{n}^{2} 121$ / $2011^{10}$, cujo objetivo era complementar ao da AP 120/2011 ${ }^{11}$, ocorreu em um momento em que o relatório final de sistematização das contribuições da audiência pública anterior ainda não havia sido publicado. A ANT'T realizou a audiência no 121/2011 em um momento em que havia questões pendentes do processo anterior. Isso prejudicou a percepção dos participantes em relação à legitimidade da segunda audiência, minorando seu potencial de efetividade.

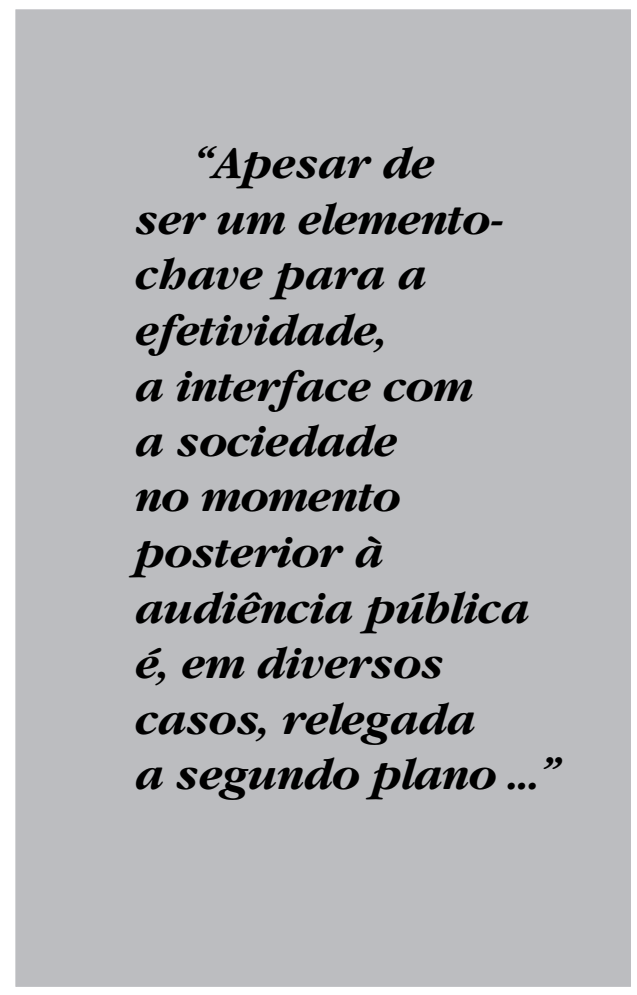

É importante lembrar que audiências públicas são eventos pontuais e seu objetivo deve ser compatível com essa característica. Portanto, diversas políticas públicas demandam outros instrumentos participativos em vez de audiências públicas e, em determinados casos, outros mecanismos de participação podem ser utilizados em complementação às 
audiências. Existe uma relação dinâmica entre os diversos instrumentos, variando, de caso a caso, o mecanismo mais adequado ou a melhor combinação deles. A depender da temática e da fase do ciclo de política pública, outros instrumentos, tais como conferências setoriais, conselhos e/ou consultas públicas, podem ser utilizados.

\section{Escopo das audiências públicas}

Por escopo de uma audiência, entendemos o recorte do objeto e a temática que será discutida e que definirá seu perfil. O escopo de uma audiência pública deve ser definido com cuidado para que os interessados tenham a possibilidade de opinar em relação aos temas que consideram importantes, mas também para que o(a) gestor(a) possa sistematizar as contribuições dos participantes de forma compatível com o objeto da audiência.

Por um lado, foi observado que a excessiva limitação do escopo pode levar a uma menor valoração do processo participativo pelas partes interessadas e, consequentemente, a uma menor percepção da legitimidade da política em questão. Por outro lado, quanto mais amplo o escopo da participação, mais difícil tende a ser a coordenação do debate e a sistematização das propostas de uma maneira trabalhável, para que sejam analisadas pelos gestores públicos e, eventualmente, incorporadas na política.

Os casos das hidrelétricas estudadas refletem bem essa questão. Esses processos foram negativamente impactados pela falta de participação popular em momentos prévios de planejamento da política e definição de diretrizes e pela falta de definição clara do escopo das AP. Assim, no momento de realização das audiências, questões como, por exemplo, a insatisfação com o modelo energético nacional e com os modelos de desenvolvimento regionais estiveram muito presentes no debate. No entanto, tais temas não pertencem ao escopo de uma audiência de licenciamento ambiental, que foca nos potenciais impactos específicos de uma obra de infraestrutura e sua viabilidade socioambiental.

Ao mesmo tempo em que a limitação do escopo do debate pode reduzir a percepção de legitimidade da audiência perante a sociedade, a qual pode ficar insatisfeita por não perceber eco por parte dos gestores governamentais aos seus anseios, um escopo demasiado amplo pode fazer com que as contribuições da sociedade sejam dispersas, fragmentadas e com grau de abrangência que vai além do que é possível ser alterado naquela fase da política. Torna-se difícil sistematizar as contribuições recebidas e menores são as chances de que a política em questão seja reformulada conforme as contribuições.

É fundamental, portanto, que o escopo de uma audiência seja definido a partir de sua temporalidade e adequação à política e que esse esteja claro desde o início tanto para os gestores quanto para as partes interessadas.

\section{Infraestrutura adequada}

Prover infraestrutura adequada ao número de participantes e ao tipo de audiência é fator essencial para que o evento tenha uma participação social efetiva. $\mathrm{Na}$ comparação entre os casos estudados, esse fator esteve associado a uma maior percepção de abertura, seriedade e comprometimento, por parte do público presente, em relação ao governo.

Recursos e infraestrutura disponibilizados - lugar de fácil acesso, espaço com capacidade para acolher os participantes, com equipe técnica capacitada e adequada 
para conduzir os trabalhos - são elementos que contribuem para a efetividade da participação.

Os casos das AP de licenciamento ambiental mostram que, por vezes, foram utilizados auditórios com tamanho avaliado pelo público presente como insuficiente para acomodar o grande número de pessoas, motivando comentários por parte da sociedade civil de que o governo não queria a presença de todos; em outro caso, os participantes afirmaram que o local escolhido tinha uma acústica ruim e que o barulho excessivo prejudicou a concentração e interação entre os participantes. Há relatos, no caso de Belo Monte, de que o transporte fornecido para garantir a presença de comunidades isoladas no evento foi deficitário. Nesses e em outros casos, a maior dificuldade relatada pelos gestores foi a de prever a quantidade de participantes, já que não havia inscrição prévia. A participação nos dois casos de licenciamento estudados foi significativa, algumas vezes chegando a mais de mil pessoas por audiência.

Já a infraestrutura das audiências do PNRS variou muito conforme a região, sendo em geral bastante satisfatória. No entanto, um caso merece destaque, por demonstrar outro elemento importante e que vai além da simples adequação física das instalações destinadas a abrigar o evento. Em São Paulo, o local escolhido para a realização da audiência foi a sede da Federação das Indústrias do Estado de São Paulo (Fiesp). Embora esse local fosse ideal para realizar as audiências em termos físicos, não o era em termos simbólicos. A Fiesp é uma tradicional representante de um dos principais grupos de interesse envolvidos na questão dos resíduos sólidos: a indústria. Esse fato gerou um sentimento, por parte dos catadores de materiais recicláveis (outro dos principais grupos de interesse na temática, cuja posição tinha pontos importantes de divergência com os interesses da indústria), de que eles não eram bem-vindos na audiência. Assim, concluiu-se que é importante identificar não somente obstáculos relativos à estrutura física, mas também sensibilidades políticas na escolha do local de realização do evento.

\section{Capacidade institucional do órgão público responsável}

Um elemento que pode ampliar o potencial de efetividade de uma audiência pública é a existência, no órgão público responsável, de uma estrutura interna voltada à participação social. Isso implica contar com documentos de referência, instalações e servidores capacitados responsáveis pela realização das AP.

Um exemplo vem dos casos de licenciamento ambiental. A falta de pessoal especializado em participação social, destacado para as audiências públicas no Ibama, pode ter prejudicado a efetividade da participação, já que os próprios servidores responsáveis pelas análises técnicas do EIA, entre outras funções, eram incumbidos de lidar também com a interface com a sociedade. Por exemplo, eles tiveram dificuldade em analisar os muitos documentos protocolados por organizações da sociedade civil. Além disso, segundo pesquisa do Banco Mundial (World BANK, 2008), no Ibama são raros os profissionais com formação em ciências humanas ou sociais, o que pode indicar, no geral, um baixo preparo de seu corpo de servidores para lidar com demandas da sociedade. Deve-se admitir que o órgão investe na capacitação de seus servidores em relação à participação social, à mediação de conflitos etc. Mas a efetividade da 
capacitação eventual de funcionários já sobrecarregados com outras tarefas tende a ser inferior à de uma equipe de especialistas destacada para as funções relacionadas à participação.

É importante que as pessoas responsáveis pela participação social tenham bom conhecimento dos regulamentos e dos procedimentos internos relacionados ao tema, mas também que tenham capacidade de lidar com as contribuições da sociedade. Além disso, perícias relacionadas à mediação de conflitos e ao diálogo social são fundamentais para que o processo participativo promova o diálogo e não a polarização - entre governo e sociedade.

Em casos em que há falta de pessoal e demais elementos de estrutura interna para a participação social, uma estratégia para compensar essa deficiência é descentralizar e compartilhar o processo de organização das audiências. O caso do PNRS mostra, por exemplo, que houve ganhos de qualidade no processo porque o Ministério do Meio Ambiente realizou as audiências em parceria com governos estaduais. Assim, o processo de divulgação e mobilização, bem como o provimento de infraestrutura (auditórios, equipamentos de áudio e vídeo, etc.), foi compartilhado entre diversos atores, compensando a falta de recursos do MMA e, ao mesmo tempo, garantindo um comprometimento político dos demais atores envolvidos. Quanto à questão da falta de pessoal tecnicamente capacitado, o MMA contratou consultores especialistas na temática de resíduos sólidos, para auxiliar no esclarecimento de dúvidas dos participantes. Isso contribuiu para que a pesada linguagem técnica da temática fosse, em parte, traduzida pelos especialistas, facilitando a participação.

\section{Neutralidade e postura pró-debate do(a) mediador(a)}

Um ponto-chave na busca por efetividade passa pelo papel do(a) mediador(a) / facilitador(a) do debate. É ele ou ela que irá dar o tom e coordenar o debate. Sua atuação tem reflexos na capacidade do público presente de participar efetivamente e na sua percepção quanto à neutralidade, à seriedade e à legitimidade do processo.

$\mathrm{Na}$ escolha do(a) mediador(a), é importante combinar três características:

A) capacitação em metodologias participativas;

B) neutralidade com relação à temática; e

C) reconhecimento do(a) mediador(a) como neutro(a) pelo público presente.

É importante ressaltar que B e C, apesar de inter-relacionadas, são características distintas. No caso das hidrelétricas do Rio Madeira, até onde pudemos observar pelas gravações de vídeo, a postura do mediador foi neutra na condução do debate. No entanto, ele - que era o diretor de licenciamento ambiental do Ibama e dividia a mesa da AP com o proponente do projeto - não era visto como neutro por todos os interessados no processo e a avaliação de sua atuação por parte do público presente foi prejudicada, o que levou a críticas, aparentemente indevidas, em relação à sua atuação.

O caso da ANT'T mostra um problema quanto à característica $\mathrm{A}$. O caráter eminentemente técnico da agência reflete-se nas capacidades de sua equipe. Dessa forma, o perfil mais técnico que político do servidor designado para atuar como mediador fez com que as audiências - apesar de contarem com boa infraestrutura e transparência - não promovessem o debate de maneira satisfatória, mantendo, do ponto de vista de alguns participantes, um foco demasiado no caráter técnico das decisões 
a serem tomadas, em detrimento do caráter político.

O caso do PNRS também ilustra uma falha na dimensão A, mas sob prisma diferente. Enquanto muitos mediadores se esforçavam para fomentar o debate e ampliar a participação, a falta de capacitação em metodologia participativa por vezes levou à falta de dimensionamento do tempo e de objetividade na condução do trabalho.

\section{Metodologias do processo partici- pativo}

Nos casos estudados, metodologias adequadas e claras, seguidas com coerência, tenderam a aumentar a percepção de legitimidade e de seriedade da AP por parte do público presente e potencializaram a capacidade dos gestores de sistematizar as propostas.

A metodologia utilizada na audiência deve ser adequada à especificidade dos participantes; à complexidade e abrangência do tema a ser debatido; aos objetivos da AP e ao tempo e recursos disponíveis para a realização do evento.

A questão da especificidade dos participantes é retratada nos casos de licenciamento ambiental. Comunidades indígenas e ribeirinhas necessitam de audiências que contemplem suas especificidades culturais e tipos de organização; que traduzam o pesado aparato técnico da política pública para a realidade local; e que levem em conta distâncias territoriais e dificuldades de acesso ao local das audiências ${ }^{12}$. Em alguns casos em que o tema é abrangente, como na formulação de políticas nacionais, é importante que as audiências abordem dimensões regionais e/ou setoriais.

Nos contextos citados, pode ser necessário que a audiência seja desmembrada em etapas focadas na participação de públicos específicos, tais como audiências locais, estaduais e regionais, e audiências com foco temático reduzido, que contemplem a complexidade do tema. Em diversos casos, é importante ampliar o tempo de realização do processo de audiência, o que pode demandar recursos extras. Apesar de a questão dos recursos ser frequentemente apontada como obstáculo à ação governamental, observamos que a restrição demasiada de tempo e a não atenção à complexidade da temática em questão podem reduzir a efetividade do processo participativo.

O desenho da audiência é parte importante da metodologia. Mas também é fundamental ter atenção à metodologia empregada por mediadores e coordenadores durante o evento. Tal metodologia direciona a participação e indica como será feita a sistematização das contribuições da sociedade. Uma das principais críticas com relação às audiências de Belo Monte e de Santo Antônio e Jirau foi que elas não contaram com uma metodologia que permitisse a sistematização das contribuições de forma trabalhável pelos(as) gestores(as).

As audiências do PNRS, por sua vez, contaram com um documento de referência, e a metodologia utilizada para o debate focava nas contribuições relativas ao documento, fazendo com que as manifestações fossem mais objetivas. Além disso, a metodologia incluía a priorização de propostas, o que permitiu identificar quais itens da política atendiam à maior parte dos presentes. Tal metodologia facilitou o trabalho dos responsáveis pela sistematização das contribuições e, consequentemente, possibilitou uma melhor consideração das contribuições pelos responsáveis pela redação da versão final do plano. Nesse caso, o nível de incorporação das contribuições e de 
satisfação dos participantes foi significativamente alto.

Ressalta-se, contudo, que, embora contasse com inovações bem-sucedidas, a metodologia utilizada no PNRS teve suas falhas. A primeira delas refere-se à falta de clareza, em certos momentos, quanto às regras procedimentais. Tais regras não foram suficientemente disponibilizadas aos participantes com antecedência e os próprios mediadores por vezes tinham dúvidas em relação à sua aplicação. Além disso, a interpretação e aplicação das regras pelos mediadores não foi totalmente coerente nas várias etapas da audiência. Isso gerou, em alguns momentos, um sentimento de confusão e incerteza por parte dos participantes, influenciando de forma negativa a sua percepção sobre a efetividade do processo. Além disso, alguns elementos da metodologia tinham um caráter deliberativo, dissonando do caráter consultivo da $\mathrm{AP}$, tais como a votação para eleger uma única proposta a ser encaminhada. Isso levou a uma percepção errada sobre o objetivo do processo. Audiências públicas são, por definição, consultivas e as audiências do PNRS não fugiram a essa regra. Mas se observou que a utilização de elementos metodológicos típicos de processos deliberativos tem o potencial de gerar insatisfação entre os participantes, que esperam que aquilo que foi votado conste no documento final.

\section{Devolutiva à sociedade}

Apesar de ser um elemento-chave para a efetividade, a interface com a sociedade no momento posterior à audiência pública é, em diversos casos, relegada a segundo plano pelos(as) gestores(as) de política pública. Esse momento deve incluir uma devolutiva clara à sociedade, indicando a incorporação ou não das contribuições, com justificativa, o que pode aumentar a percepção de legitimidade da audiência pública.

Para que seja possível promover uma devolutiva formal, é preciso que tenha havido um processo adequado de sistematização das propostas. Isso implica, como apontado anteriormente, que a audiência tenha empregado uma metodologia adequada para esse fim e, também, que o órgão responsável pela AP tenha capacidade institucional para analisar as contribuições recebidas.

Entre os estudos de caso incluídos nesta pesquisa, os de licenciamento ambiental são exemplos em que a falta de devolutiva formal gerou insatisfação na sociedade, que viu nesse fato um indício de que as audiências públicas haviam tido efeitos limitados na política em questão. Nesses casos, não houve uma sistematização dos resultados das audiências e, como consequência, não houve uma devolutiva para a sociedade.

Já os casos do PNRS e da ANTT incluíram devolutivas para a sociedade. No caso do PNRS, a primeira devolutiva ocorreu na audiência nacional em Brasília/ DF, quando houve a disponibilização de uma nova versão do documento de referência, incorporando as contribuições oriundas das audiências regionais, que haviam ocorrido anteriormente. Essa iniciativa (e o conteúdo do documento) ampliou a percepção de seriedade e efetividade da participação entre os presentes, que reconheceram que o documento contemplava parte significativa das contribuições oriundas das audiências regionais.

A ANT'T promoveu a devolutiva da AP no 120/2011 em um relatório de conteúdo claro e detalhado, inclusive com a análise e justificativa para o acatamento ou não de cada contribuição. O problema em 
relação a esse caso foi o prazo em que a devolutiva ocorreu, em momento posterior ao início do processo da audiência no 121 / 2011, que era vista pelos participantes como audiência complementar à de n⿳丷ㅜ120/ 2011. Consequentemente, para os participantes, a continuidade da participação na AP no 121/2011 foi prejudicada, uma vez que não conheciam o resultado da outra fase do processo.

\section{Transparência}

É necessário que todo o processo de audiência pública seja pautado pela transparência. A publicidade de informações deve acompanhar todas as fases do processo: seja na divulgação e na mobilização dos atores relevantes; na disponibilização e acessibilidade de documentos de referência; sobre a clareza dos objetivos da audiência e da metodologia utilizada; e sobre o que será feito com as contribuições da sociedade.

Nesse aspecto, o procedimento da ANT'T foi exemplar. Informações sobre prazos, metodologia, contribuições, documentos de referência, atas, entre outros elementos importantes foram disponibilizados no site da agência. Isso foi essencial para que os interessados tivessem uma participação mais informada e fosse gerado um sentimento de confiança da sociedade para com o órgão governamental. No caso do PNRS, houve reclamações quanto à divulgação deficitária do evento; ao reduzido prazo entre a disponibilização dos documentos de referência e a audiência pública $^{13}$; e com relação à falta de clareza sobre a metodologia. Mas é importante ressaltar que não há nenhuma evidência de que os problemas das audiências do PNRS tenham resultado de uma postura ativa dos(as) gestores(as) no sentido de reduzir a transparência, mas, sim, de falhas de organização por parte dos órgãos responsáveis pelo evento e do curto tempo disponível devido a prazos legais.

Nos casos de Belo Monte e Santo Antônio e Jirau, por sua vez, as principais reclamações quanto à transparência, ou seja, quanto ao acesso a informações confiáveis e de qualidade, se concentram no EIA-Rima, que é o principal documento a ser debatido na audiência. Uma primeira crítica se refere a dúvidas quanto à independência da empresa de consultoria responsável por realizar o estudo, já que quem escolhe e paga a consultora é a empresa proponente do projeto. Dessa forma, há dúvidas quanto à liberdade dos técnicos contratados de criticar os planos e ações da empresa contratante.

Além disso, em ambos os casos, apesar de o EIA, o Rima e vários outros documentos estarem disponíveis em forma digital no site do Ibama, foram identificadas reclamações por parte da sociedade quanto ao acesso on-line a outros documentos relevantes. Até então, os autos dos processos não eram digitalizados e disponibilizados no site, dificultando o acesso dos interessados, que tinham que se deslocar até Brasília ou requerer uma cópia, arcando com custos relativamente altos. Recentemente, o Ibama começou a digitalizar os autos em sua integralidade e disponibilizá-los on-line, aumentando de maneira significativa a transparência e facilitando a participação, além de reduzir custos para o próprio governo federal. Esse é um bom exemplo que deveria ser seguido por toda a administração pública.

Houve insatisfação também quanto à linguagem utilizada nos relatórios, considerada muito técnica e prejudicial à compreensão por parte de muitos atores interessados, tais como comunidades indígenas e ribeirinhas. Dessa forma, seria 
interessante que fossem disponibilizadas diversas versões dos relatórios sobre o empreendimento, os benefícios e os impactos esperados, com diferentes linguagens e níveis de complexidade técnica.

\section{Considerações finais}

As conclusões aqui expostas são provenientes de uma pesquisa que teve a duração de um ano e contou com quatro estudos de caso. A partir da análise da bibliografia, de análise documental e de entrevistas com participantes e organizadores das AP, foram identificados fatores que influenciam o potencial de efetividade da participação social em audiências públicas. Procurouse compreender como variações nesses fatores podem interferir na referida efetividade, de modo a aperfeiçoar o uso das audiências públicas como instrumento de participação.

No entanto, tendo em vista a limitação a quatro casos, as conclusões desta pesquisa não são passíveis de generalização. Não há como afirmar que a adoção de medidas identificadas nos casos como elemento de sucesso (ou o esforço em evitar elementos que contribuíram para minorar o potencial de efetividade) será bem-sucedida em qualquer caso, tendo em vista a limitação de escopo desta pesquisa e porque elementos contextuais são fundamentais para a efetividade de processos participativos. Destaca-se, contudo, que os diversos estudos apontados no referencial teórico permitem afirmar que a participação social amplia a capacidade de governo e a efetivação do processo de gestão das políticas públicas.

As conclusões aqui apresentadas apontam boas práticas e gargalos na organização de audiências públicas. Essas conclusões, empiricamente fundamentadas, certamente serão úteis tanto para gestores públicos responsáveis pela organização e gestão desses espaços participativos quanto para estudiosos que pretendem desbravar um campo de estudos ainda pouco explorado. Além de responder à pergunta de pesquisa, as análises apresentadas neste artigo têm o potencial de servir como catalisador do debate contínuo sobre o tema, agregando a teoria e a experiência prática de gestores envolvidos com a realização de audiências públicas. Espera-se, assim, que as informações compiladas tomem vida própria e se desenvolvam com o acúmulo de novas ideias, teorias e experiências.

(Artigo recebido em janeiro de 2013. Versão final em março de 2013).

\section{Notas}

${ }^{1}$ Para mais informações e análises relacionadas ao SIGPlan, consultar o relatório preliminar de pesquisa (Ipea, 2012), disponível em wnm.ipea.gov.br/participacao .

${ }^{2}$ Elaboração do Plano Nacional de Resíduos Sólidos e Licitação e Contrato de Permissão dos Serviços de Transporte Rodoviário Interestadual de Passageiros (da ANTT).

${ }^{3}$ Licenciamento das hidrelétricas de Santo Antônio e Jirau, em Rondônia, e de Belo Monte, no Pará. 
${ }^{4}$ Para uma análise detalhada e completa sobre cada um dos quatro casos estudados, consultar o relatório final de pesquisa, disponível em: wmw.ipea.gov.br/participacao.

${ }^{5}$ O diagnóstico foi elaborado pela equipe da Diretoria de Estudos e Políticas Regionais, Urbanas e Ambientais (Dirur), do Instituto de Pesquisa Econômica Aplicada (Ipea).

${ }^{6} \mathrm{O}$ plano de outorga traz os aspectos técnicos necessários para a prestação do serviço público.

${ }^{7}$ Esse projeto foi objeto de inúmeras audiências em outros momentos e espaços, como as realizadas pelo Ministério Público e pelo Poder Legislativo. Devido ao escopo limitado do presente estudo, o foco foi somente no processo de licenciamento ambiental, não tendo sido possível analisar os demais fóruns de discussão.

${ }^{8}$ Ver Quadro 2.

${ }^{9}$ No momento da pesquisa, o governo federal estava realizando um amplo processo de consulta, no intuito de regulamentar o mecanismo de consulta prévia previsto na Convenção 169 da OIT.

${ }^{10} \mathrm{O}$ objetivo da audiência pública $\mathrm{n}^{\circ}$ 121/2011 foi coletar contribuições sobre as Minutas do Edital de Licitação e Contrato de Permissão dos Serviços de Transporte Rodoviário Interestadual de Passageiros, operados por ônibus do tipo rodoviário.

${ }^{11}$ O objetivo da audiência pública no 120/2011 foi a discussão do plano de outorga sobre os serviços de transporte rodoviário interestadual de passageiros, operados por ônibus do tipo rodoviário.

12 A Convenção 169 da Organização Internacional do Trabalho (OIT), ratificada pelo Brasil, prevê a realização de consulta prévia a povos indígenas e tribais, no caso de empreendimentos e políticas públicas que tenham impacto nessas comunidades.

${ }^{13}$ Esse fato foi observado também no caso de Belo Monte, no qual houve reclamações da sociedade civil sobre o fato de os últimos volumes do EIA somente terem sido disponibilizados poucos dias antes da primeira AP.

\section{Referências bibliográficas}

Alencar, J. ; Fonseca, I. ; Cruxên, I. ; Pires, R.; Ribeiro, U. Participação Social e Desigualdades nos Conselhos Nacionais. $8^{\circ}$ Encontro da Associação Brasileira de Ciência Política (ABCP), Gramado/RS, 2012.

Avritzer, L. (Org.). Experiências nacionais de participação social. Belo Horizonte: Cortez Editora, 2010.

. Conferências Nacionais: Ampliando e Redefinindo os Padrões de Participação Social no Brasil. Texto par discussão, 1739. Rio de Janeiro: Ipea, 2012.

Barros, T; Ravena, N. Representações sociais nas audiências públicas de Belo Monte: do palco ao recorte midiático. IV Encontro da Compolítica, UERJ, 2011.

Brasil. Plano Nacional de Resíduos Sólidos - Versão preliminar para Consulta. Ministério do Meio Ambiente, 2011. 
Cleaver, F. Institutions, agency and the limitations of participatory approaches to development. In: Cooke, B.; Kothari, U. (Org.). Participation: the new tyranny? New York: Zed Books, 2001.

. The inequality of social capital and the reproduction of chronic poverty. World Development, v. 33, n. 6, p. 893-906, 2005.

Fonseca, I; Bursztyn, M; Moura, A. Conhecimentos Técnicos, Políticas Públicas e Participação: O Caso do Conselho Nacional do Meio Ambiente (CONAMA). Revista de Sociologia e Política, v. 20, p. 183-198, 2012.

Fuks, M.; PerissinotTo, R. Recursos, decisão e poder: conselhos gestores de políticas públicas de Curitiba. Revista Brasileira de Ciências Sociais, v. 21, n. 60, p. 67-81, 2006.

Grau, N. Controly participación social en la administración federal brasileira: balance y perspectivas. Relatório de Pesquisa. Ministério de Planejamento, Orçamento e Gestão/World Bank/PNUD, 2011.

. Modelos de controle e de participação sociais existentes na administração pública federal. Relatório de Pesquisa. Ministério de Planejamento, Orçamento e Gestão /World Bank/PNUD, 2010.

IpeA. Instituto de Pesquisa Econômica Aplicada. Audiências Públicas no Âmbito do Governo Federal: Análise preliminar e bases para avaliação. Relatório de pesquisa. Brasília: IPEA, 2012. Disponível em: www.ipea.gov.br/participação.

. Efetividade das Instituições Participativas no Brasil: estratégias de avaliação. Roberto Rocha C. Pires. (Org.). v. 7, 372 p., 2011.

. Potencial de Efetividade das Audiências Públicas do Governo Federal: relatório de conclusão da pesquisa. Brasília: IPEA, 2013. no prelo. Disponível em: www.ipea.gov.br/ participação.

Kothari, U. The case for participation as tyranny. In: Cooke, B.; Kothari., U. (Org.). Participation: the new tyranny? New York: Zed Books, 2001. p. 1-15.

MANOR, J. User committees: a potentially damaging second wave of descentralization? The European Journal of Development Research, v. 16, n. 1, p. 192-213, 2004.

MatTos, P. Regulação econômica e social e participação pública no Brasil. IX Congreso Internacional del Clad sobre la Reforma del Estado y de la Administración Pública. Madrid, Espanha, 2004.

Ortiz, L. O maior tributário do Rio Amazonas Ameaçado. Hidrelétricas no Rio Madeira, 2007. Disponível em: http:// mwn.riosvivos.org.br/dowloads/rio_madeira_portugues.pdf. Acessado em: 15/05/2012.

Pires, R; VAZ, A. Participação social como método de governo? Um mapeamento das interfaces socioestatais no governo federal. Texto para discussão, 1707. Rio de Janeiro: Ipea, 2012.

Pires, R; Vaz, A.; Almeida, A.; Silva, F.; Lopez, F.; Alencar, J. Em Busca de uma Síntese: Ambições comuns e abordagens diversificadas na avaliação da efetividade das instituições participativas. In: Roberto Rocha C. Pires. (Org.). Efetividade das Instituições Participativas no Brasil: Estratégias de Avaliação. Brasília: IPEA, 2011, v. 7, p. 347-364.

Pogrebinschi, T. Conferências Nacionais e Políticas Públicas Para Grupos Minoritários. Texto para discussão, 1741. Rio de Janeiro: Ipea, 2012. 
REZENDE, R. Navigating the turbulent waters of public participation in Brazil: a case study of the Santo Antônio and Jirau hydroelectric dams. 2009. Dissertação de mestrado. Utrecht University.

SAYAGO, D. Os conselhos de desenvolvimento territorial: entre a participação e a representação. Revista Brasileira de Gestão e Desenvolvimento Regional, v. 3, n. 4, p. 9-21, 2007.

Serafim, L. Controle social nas Agências Reguladoras Brasileiras: entre Projetos Políticos e Modelo Institucional: a ANEeL nos governos FHC e Lula. 2007. Dissertação de Mestrado, Universidade Estadual de Campinas.

SoAres, E. A audiência pública no processo administrativo. Jus Navigandi, 2002. Disponível em: http://jus.uol.com.br/revista/texto/3145. Acesso em: 08/08/2011.

SouzA, C. A que vieram as conferências nacionais? Uma análise dos objetivos dos processos realizados entre 2003 e 2010. Texto para discussão, 1718. Rio de Janeiro: Ipea, 2012. SouZA, W; ReID, J. Uncertainties in Amazon Hydropower Development: Risk Scenarios and Environmental Issues around the Belo Monte Dam. Water Alternatives, v. 3, n. 2, pp. 249-268, 2010.

Vasconcelos, P. A audiência pública como instrumento de participação popular na avaliação do estudo de impacto ambiental. 2002. Dissertação de mestrado, Universidade Federal de Pernambuco.

World BANK. Environmental licensing for bydroelectric projects in Brazil. Summary Report. World Bank, 2008. 


\section{Resumo - Resumen - Absctract}

Audiências públicas: fatores que influenciam seu potencial de efetividade no âmbito do Poder Executivo federal

Igor Ferraz. Fonseca, Raimer Rodrigues Rezende, Marília Silva de Oliveira e Ana Karine Pereira

Este artigo apresenta os principais resultados e as principais conclusões de uma pesquisa aplicada que visou a responder a seguinte pergunta: "No âmbito do Poder Executivo federal, quais são os principais fatores que influenciam o potencial de efetividade das audiências públicas como mecanismo de participação social no processo de gestão das políticas públicas?”. Para tanto, e a partir de metodologia qualitativa, o estudo contou com quatro estudos de caso de audiências realizadas por órgãos do governo federal: a elaboração do Plano Nacional de Resíduos Sólidos; a discussão das minutas do Edital de Licitação e Contrato de Permissão dos Serviços de Transporte Rodoviário Interestadual de Passageiros; e o licenciamento ambiental de dois grandes projetos de usinas hidrelétricas - Santo Antônio/Jirau e Belo Monte. Os resultados da análise empírica apontam fatores importantes que têm impacto na efetividade das audiências. Essa análise teve por objetivo fornecer subsídios para gestores públicos responsáveis pela organização e realização desses processos participativos, bem como para estudiosos envolvidos com o tema.

Palavras-chave: audiências públicas; participação social; resíduos sólidos; transporte rodoviário; licenciamento ambiental

Audiencias públicas: factores que influyen en su potencial de efectividad en el ámbito del Poder Ejecutivo federal

Igor Ferraz. Fonseca, Raimer Rodrigues Rezende, Marilia Silva de Oliveira y Ana Karine Pereira

En este artículo se presentan los principales resultados y las principales conclusiones de una investigación aplicada cuyo objetivo era responder a la siguiente pregunta: "Dentro del Poder Ejecutivo federal, ¿cuáles son los principales factores que influyen en el potencial de efectividad de las audiencias públicas como mecanismo de participación social en el proceso de gestión de las políticas públicas?". Para ello, y mediante el uso de una metodología cualitativa, el estudio se basó en cuatro estudios de caso de audiencias realizadas por agencias del Gobierno federal: la preparación del Plan Nacional de Manejo de los Desechos Sólidos; la discusión sobre el proyecto del documento de licitación y sobre el contrato de autorización para explotar servicios de autobuses interestatales; $y$ licencias ambientales para dos grandes proyectos hidroeléctricos - Santo Antônio/Jirau y Belo Monte. Los resultados del análisis empírico indican factores importantes que afectan a la eficacia de las audiencias. Este análisis tuvo como objetivo proveer subsidios para los gestores públicos responsables de la organización y realización de estos procesos participativos, así como académicos interesados en el tema.

Palabras clave: audiencias públicas; participación social; desechos sólidos; transporte en autobuses; licencias ambientales 
Public hearings: the factors that impact the potential of their effectiveness in the management process of public policy

Igor Ferraz Fonseca, Raimer Rodrigues Rezende, Marília Silva de Oliveira and Ana Karine Pereira

This article presents the main results and the main conclusions of an applied research that aimed to answer the following question: "within the Federal Executive Branch, what are the main factors that impact the potential of effectiveness of public hearings as a mechanism of social participation in the management process of public policy?". For this purpose, and through the use of qualitative methodology, the research relied on four case studies of hearings held by Federal Government agencies: the preparation of the National Solid Waste Management Plan; the debate on the drafts of the bidding terms and conditions, and regarding the contract of permission to exploit Interstate Bus Services; and the environmental licensing of two major hydroelectric projects - Santo Antônio/Jirau and Belo Monte. The results of the empirical analysis point out important factors that impact the effectiveness of the hearings. This analysis aimed to provide subsidies for public managers responsible for organizing and conducting these participatory processes, as well as for scholars concerned with the issue.

Keywords: public hearings; social participation; solid waste; road transport; environmental licensing

Igor Ferraz Fonseca

Sociólogo e mestre em Política e Gestão Ambiental pela Universidade de Brasília. Técnico de Planejamento e Pesquisa, da Diretoria de Estudos e Políticas do Estado, das Instituições e da Democracia (Diest) do Instituto de Pesquisa Econômica Aplicada (Ipea). Contato: igor.fonseca@ipea.gov.br

Raimer Rodrigues Rezende

Antropólogo pela Universidade de Amsterdam e mestre em Desenvolvimento Sustentável e Política Ambiental pela Universidade de Utrecht. Pesquisador do Programa de Pesquisa para o Desenvolvimento Nacional (PNPD), na Diretoria de Estudos e Políticas do Estado, das Instituições e da Democracia (Diest) do Instituto de Pesquisa Econômica Aplicada (Ipea).Contato: raimer.rezende@ipea.gov.br

Marília Silva de Oliveira

Cientista Política, mestre em Ciências Sociais e doutoranda em Ciência Política pela Universidade de Brasília. Ex-pesquisadora do Programa de Pesquisa para o Desenvolvimento Nacional (PNPD), na Diretoria de Estudos e Políticas do Estado, das Instituições e da Democracia (Diest) do Instituto de Pesquisa Econômica Aplicada (Ipea). Contato: mariliasoliveira@gmail.com

Ana Karine Pereira

Cientista Política, mestre e doutoranda em Ciência Política pela Universidade de Brasília. Pesquisadora do Programa de Pesquisa para o Desenvolvimento Nacional (PNPD), na Diretoria de Estudos e Políticas do Estado, das Instituições e da Democracia (Diest) do Instituto de Pesquisa Econômica Aplicada (Ipea). Contato: ana.pereira@ipea.gov.br 